\title{
Involvement of VCAM1 in the bovine conceptus adhesion to the uterine endometrium
}

\author{
Rulan Bai, Hanako Bai ${ }^{\dagger}$, Mariko Kuse ${ }^{1}$, Atsushi Ideta ${ }^{2}$, Yoshito Aoyagi ${ }^{2}$, Hiroshi Fujiwara ${ }^{3}$, \\ Kiyoshi Okuda ${ }^{1}$, Kazuhiko Imakawa and Toshihiro Sakurai ${ }^{\ddagger}$ \\ Laboratory of Theriogenology and Animal Breeding, Graduate School of Agricultural and Life \\ Science, the University of Tokyo, 1-1-1 Yayoi, Bunkyo-ku, Tokyo 113-8657, Japan, ${ }^{1}$ Laboratory of Reproductive \\ Physiology, Graduate School of Environmental and Life Science, Okayama University, Okayama 700-8530, Japan, \\ ${ }^{2}$ Zennoh Embryo Transfer Center, Kamishihoro, Hokkaido 080-1407, Japan and ${ }^{3}$ Faculty of Medicine, \\ Institute of Medical, Pharmaceutical and Health Sciences, Kanazawa University, Kanazawa 920-5111, Japan
}

Correspondence should be addressed to K Imakawa; Email: akaz@mail.ecc.u-tokyo.ac.jp

${ }^{+} \mathrm{H}$ Bai is now at Mito Research Center, Meiji Feed Co. Ltd, 870 Wakamiya, Ibaraki-machi, Ibaraki 311-3123, Japan " T Sakurai is now at Department of Occupational and Environmental Health, Faculty of Pharmaceutical Science, Tokyo University of Science, 2641 Yamazaki, Noda-shi, Chiba 278-8510, Japan

\begin{abstract}
Following bidirectional communication, the conceptus and the uterine epithelium must establish a proper cell-cell interaction, resulting in the progression of implantation processes. To clarify the mechanism of conceptus attachment to the uterine endometrium, we studied whether vascular cell adhesion molecule (VCAM1) was expressed in bovine conceptuses or endometrium during the peri-attachment period. Uterine VCAM1 expression was minimal in day 17 (day $0=$ day of estrus) cyclic and pregnant animals, but increased between days 20 and 22 of pregnancy. In the intercaruncular regions, VCAM1 protein was localized to the luminal and glandular epithelia, whereas in the caruncular regions, VCAM1 protein was detected in the stroma and endothelia of the uterine endometrium. In cultured endometrial epithelial cells (EECs), VCAM1 expression was up-regulated when treated with uterine flushings or growth factor and further increased when EECs were cocultured with bovine trophoblast CT1 cells. VCAM1 expression in CT1 cells was also up-regulated with the use of uterine flushings, and further increased when these cells were cocultured with EECs. Expression of VCAM1 receptor, integrin $\alpha 4$ (ITGA4) mRNA, increased significantly in day 22 conceptuses. In day 22 pregnant uteri, VCAM1 protein was found in both EECs and conceptuses, but ITGA4 was localized only to trophoblasts. These observations indicate that cell-cell interactions between conceptuses and uterine epithelial cells are required for sufficient VCAM1 and ITGA4 expression in the bovine species and suggest that uterine VCAM1 and conceptus ITGA4 play a role in the establishment of conceptus adhesion to the uterine endometrium.

Reproduction (2014) 148 119-127
\end{abstract}

\section{Introduction}

In the bovine species, a significant fraction of embryonic losses occurs during the peri-implantation period, resulting from insufficient biochemical communication between the elongating conceptus and the uterus (Diskin \& Morris 2008). It is well documented that cell-cell interactions and integrin (ITG)-mediated signaling between the conceptus and endometrium are critical for successful implantation in humans and murine species (Aplin et al. 1998, Armant 2005). Specifically, the extracellular domain of ITGs acts as a receptor for extracellular matrix components (ECMs) such as fibronectin, vitronectin, laminin, collagen type IV, and osteopontin (SPP) (Akiyama 1996, Armant 2005). In goats, sheep, and cattle, constituents of uterine histotroph such as interferon gamma-inducible protein 10
(CXCL10), galactoside-binding, soluble, 15 (LGALS15), and insulin-like growth factor-binding protein 1 (IGFBP1) have been characterized to activate ITGs through their RGD domain during the trophectoderm attachment period (Nagaoka et al. 2003, Farmer et al. 2008, Simmons et al. 2009). In the bovine species, the expression of ITGs has been characterized at the uteroplacental interface during the periods of trophectoderm attachment (MacLaren \& Wildeman 1995, Maclntyre et al. 2002) and placentation (Pfarrer et al. 2003). ITGs characterized in the stages of bovine trophoblast giant cell migration and fusion with the uterine epithelial cells consist of five $\alpha$-subunits (ITGA2B, ITGA3, ITGA5, ITGA8, and ITGAV) and two $\beta$-subunits (ITGB1 and ITGB3) (Pfarrer 2006). In our previous investigation (Yamakoshi et al. 2012), integrin subunits $\alpha$ (ITGAV and ITGA5) and $\beta$ (ITGB1, ITGB3, and ITGB5) are 
constitutively expressed in bovine peri-attachment trophoblast cells, whereas the expression of ITGA4 and ITGA8 are induced after attachment of trophoblast cells to uterine endometrial epithelial cells (EECs) is initiated. In spite of these efforts, our knowledge is not sufficient to improve conceptus attachment and adhesion to the uterine epithelium in the bovine species.

Vascular cell adhesion molecule (VCAM1), a transmembrane glycoprotein member of the immunoglobulin gene superfamily (Osborn et al. 1989), is known to be present in the reproductive tracts of mammalian species. In humans, for example, VCAM1 is present on the endometrial side, specifically localized to decidual stromal cells in the areas where migrating blastocysts are present, but not on vascular endothelial cells in decidua parietalis. Endometrial expression of VCAM1 at the peri-implantation stage in patients with unexplained infertility was significantly lower than in control patients (Konac et al. 2009), suggesting that the expression of VCAM1 might be essential for the preparation of the endometrium for invasive blastocyst implantation. In Vcam1 gene ablation study (Gurtner et al. 1995), the allantois fails to fuse with the chorion, resulting in abnormal placental development and embryonic losses at 9.5-11.5 days of gestation, although a minority of Vcam1-deficient mice with abnormal distribution of allantoic mesoderm over the chorionic surface survive. In the study on early pregnancy in sheep, VCAM1 is first found in endothelial cells on days 17-19 in both caruncular and intercaruncular areas of the endometrium and becomes strongly induced in endothelial cells on days 26-27 (Rahman et al. 2004). However, VCAM1 in the uterine endometrium and/or conceptuses in the context of cell-cell interactions have not been studied during early pregnancy period in limited invasive implantation of ruminants.

VCAM1, induced by various cytokines in different tissues or organs in mice (Henninger et al. 1997), functions through integrin $\alpha 4 \beta 1$ (Itga4/Itgb1), also known as very late antigen 4 (Vla4) (Denucci et al. 2009). Homozygous loss of Itgb1 expression in mice was lethal during early post-implantation development, resulting in inner cell mass failure (Stephens et al. 1995). It was also identified that homozygous Itga4 knockout mice fail to complete fusion of the allantois with the chorionic membrane during placentation period (Yang et al. 1995). In our previous investigation on bovine conceptuses, ITGA4 mRNA expression was found at elevated levels on day 22, 2-3 days after the initiation of trophoblast attachment to the endometrial epithelium (Yamakoshi et al. 2012). We also found that changes in trophoblast gene expression including ITGs were observed when bovine trophoblast CT1 cells were cocultured with EECs, which was further enhanced with the addition of uterine flushings obtained from pregnant animals (Sakurai et al. 2012). These results suggest that components of uterine flushings/histotroph including ECMs and/or various cytokines, as well as cell-cell interactions, are important in the progression of conceptus attachment to the uterine epithelium in the bovine species.

In this study, we therefore examined the expression of VCAM1 and its receptor ITGA4 in the bovine conceptus and endometrium during the peri-implantation period. Using two types of endometrial epithelial cultures, EECs alone (monoculture) or EECs cultured with CT1 cells (coculture), the experiments were extended to examine if components of uterine flushings and/or cell-cell interaction were required for the regulation of VCAM1 transcript and protein expression.

\section{Materials and methods}

\section{Animals, tissue collection, and uterine flushing preparation}

All animal procedures included in this study were approved by the Committee for Experimental Animals at Zennoh Embryo Transfer (ET) Center and the University of Tokyo. Estrous synchronization, superovulation, and ET processes were performed as described previously (Ideta et al. 2007). In this study, 30 embryos derived from the superovulation process were transferred non-surgically into the uterine horn of 15 Holstein heifers (two blastocysts/recipient), ipsilateral to the corpus luteum on day 7 (day $0=$ day of estrus) of the estrous cycle. For RNA analyses, elongated conceptuses were collected nonsurgically by uterine flushing on day 17,20 , or 22 ( $n=3$ each day) with $500 \mathrm{ml}$ sterile PBS (pH 7.2). Conceptuses in the uterine flushing media were obtained by centrifugation at $1000 \mathrm{~g}$ for 5 min and snap frozen in liquid nitrogen. Following conceptus removal, the media and those from day 17 cyclic animals $(n=3)$ were further centrifuged at $4000 \mathrm{~g}$ for $5 \mathrm{~min}$ to remove cell debris, supernatants were filtered through $0.22-\mu \mathrm{m}$ membrane, and then samples were stored at $-80{ }^{\circ} \mathrm{C}$ until use. After thawing, the samples $(10 \mathrm{ml}$ from $500 \mathrm{ml}$ uterine flushings) were concentrated and desalinated using a Micron filter device (Ultracel YM-3, Millipore, Billerica, MA, USA). Protein concentrations were determined with the Bradford reagent (Bio-Rad Laboratories) and the concentrations adjusted to $1 \mu \mathrm{g} /$ $\mathrm{ml}$ with distilled water. For immunohistochemistry, hysterectomy was performed on days 20 and 22 ( $n=3$ each day), the uteri containing conceptus tissues were frozen in dry ice-cooled heptane. For endometrial tissue collection, uterine biopsy samples $(10 \times 5 \times 5 \mathrm{~mm})$ were obtained non-surgically from day 17 cyclic and days 17,20 , and 22 pregnant animals, all of which were frozen immediately. Samples were transferred to the Laboratory of Animal Breeding at the University of Tokyo and stored at $-80{ }^{\circ} \mathrm{C}$ until use.

\section{Cell preparation and culture condition}

Bovine trophoblast CT1 cells (Talbot et al. 2000), a generous gift from Dr Alan Ealy, Virginia Polytechnic Institute, were cultured on six-well plates coated with Matrigel (Japan BD Biosciences, Tokyo, Japan) at $37^{\circ} \mathrm{C}$ in an atmosphere of $5 \%$ 
$\mathrm{CO}_{2}$ in DMEM (Wako Pure Chemical Industries, Ltd., Osaka, Japan) containing $10 \%(\mathrm{v} / \mathrm{v})$ fetal bovine serum $(\mathrm{JRH}$ Biosciences, Lenexa, KS, USA) supplemented with $4.5 \mathrm{~g} / \mathrm{l}$ D-glucose (Invitrogen), non-essential amino acids (Invitrogen), $2 \mathrm{mM}$ glutamine (Invitrogen), $2 \mathrm{mM}$ sodium pyruvate (Invitrogen), $55 \mu \mathrm{M}$ mercaptoethanol (Invitrogen), and antibiotic/antimycotic solution (Invitrogen). The medium was replaced with the fresh one every 2 days for up to 14 days.

Primary bovine EECs were isolated and cultured as described previously (Skarzynski et al. 2000). In brief, uteri of healthy Holstein cows were obtained from a local abattoir in accordance with protocols approved by the local Institutional Animal Care and Use Committee. Uteri of the early luteal phase (days 2-5) were excised and immediately transported to the laboratory. To detach EECs, the uterine lumen was trypsinized $(0.3 \% \mathrm{w} / \mathrm{v})$, from which EECs were isolated (Skarzynski et al. 2000). The isolated EECs were cultured on collagen type IA-coated six-well plates in DMEM/F12 (1:1) medium supplemented with $10 \%(\mathrm{v} / \mathrm{v})$ newborn calf serum (NBCS, Invitrogen), 40 units $/ \mathrm{ml}$ of penicillin, and $40 \mu \mathrm{g} / \mathrm{ml}$ of streptomycin at $37^{\circ} \mathrm{C}$ in an atmosphere of $5 \% \mathrm{CO}_{2}$ in humidified air. EECs were used within four passages to avoid changes in cell characteristics, specifically down-regulation of steroid receptor expression (Sakurai et al. 2012). In this study, cultured EECs maintained their characteristic intermediate filaments, in that epithelial cells expressed an epithelial cell marker, cytokeratin, and a mesenchymal cell marker, vimentin. Cytokeratin-positive epithelial cells frequently acquire vimentin during culture (Zeiler et al. 2007, Sakurai et al. 2012). In monocultures, EECs placed onto collagen type IA-coated six-well dishes were incubated with $10 \mu$ g proteins from the day 22 bovine uterine flushing, epidermal growth factor (EGF) $(1,5$, $10,20$, and $40 \mathrm{ng} / \mathrm{ml})$, basic fibroblast growth factor (bFGF) (1, $2.5,5,10$, and $20 \mathrm{ng} / \mathrm{ml})$, or IFNT $(0.01,0.05,0.1,1$, and $10 \mu \mathrm{g} / \mathrm{ml}$ ) in serum-free DMEM/F12 for $48 \mathrm{~h}$.

In coculture experimentations, EECs were initially cultured on collagen type IA-coated six-well plates to reach more than $90 \%$ confluence in NBCS-containing DMEM, followed by maintenance culture in serum-free DMEM for $24 \mathrm{~h}$. Concurrently, CT1 cells, cultured for 14 days, were treated with $1 \mathrm{ml}$ fresh medium and CT1 cells were detached from the culture dish by pipetting. These media were pooled $(6 \mathrm{ml})$, and $1 \mathrm{ml}$ medium containing CT1 cells was placed onto a confluent layer of EECs, resulting in $\sim 200 \mathrm{CT} 1$ spheroids per well (Sakurai et al. 2012). These coculture plates were then placed onto a shaker at $37{ }^{\circ} \mathrm{C}$ for $48 \mathrm{~h}$ under $5 \% \mathrm{CO}_{2}$ in humidified air. To collect CT1 cells from cocultured CT1/EECs without uterine cell contaminations, the cells in the culture medium were passed through a $70 \mu \mathrm{m}$ cell strainer (Japan BD Biosciences), and the cells that remained on the membrane were purified further by the Percoll gradient method (Sakurai et al. 2012). The cell viability was more than $95 \%$ when tested for the ability of cells to exclude trypan blue. CT1 cells were then harvested from the culture medium by centrifugation at $400 \mathrm{~g}$ for $4 \mathrm{~min}$ and subjected to RNA isolation. After CT1 cell collection, the coculture plates were washed twice with PBS, the absence of CT1 cells were verified using a microscope, and EECs were then subjected to RNA isolation or fixed with $4 \%$ paraformaldehyde/PBS for immunostaining analysis.

\section{RNA extraction and quantitative RT-PCR}

Total RNA was isolated from conceptuses, uterine tissues, or cultured CT1 or EECs with the ISOGEN reagent (Nippon Gene, Tokyo, Japan) according to the protocol provided by the manufacturer. For real-time PCR analyses, isolated RNA (total $0.5 \mu \mathrm{g}$ ) was reverse transcribed to cDNA using the ReverTra Ace qPCR RT Kit (Toyobo, Osaka, Japan) including $1 \times$ RT buffer, Enzyme Mix, and Primer Mix in a $10 \mu \mathrm{l}$ reaction volume, and the resulting cDNA (RT template) was stored at $4{ }^{\circ} \mathrm{C}$ until use.

The CDNA reaction mixture was diluted 1:10 using DNaseand RNase-free molecular biology grade water and $3 \mu$ l were subjected to real-time PCR amplification using the Thunderbird SYBR qPCR Mix Kit (Toyobo) with primers listed in Table 1, and PCR amplification was carried out on an Applied Biosystems 7900HT real-time PCR System (Applied Biosystems). The thermal profile for real-time PCR consisted of 40 cycles at $95^{\circ} \mathrm{C}$ for $10 \mathrm{~s}$, annealing at $60^{\circ} \mathrm{C}$ for $20 \mathrm{~s}$, and extension at $72{ }^{\circ} \mathrm{C}$ for $40 \mathrm{~s}$. Amplification efficiencies of each target and the reference gene, bovine $\beta$-actin $(A C T B)$, were examined through their calibration curves and found to be comparable (Bustin et al. 2009, Sakurai et al. 2012). Average threshold (Ct) values for each target were determined using Sequence Detection System software v1.2 (Applied Biosystems). Each run was completed with a melting curve analysis to confirm the specificity of amplification and the absence of primer dimer.

\section{Immunohistochemistry}

Immunohistochemical analyses were performed on $10 \mu \mathrm{m}$ fresh-frozen sections of days 20 and 22 uterine tissues. Frozen sections were fixed with $4 \%$ paraformaldehyde/PBS, and endogenous peroxidase was quenched by immersing in $0.3 \%$ $(\mathrm{v} / \mathrm{v})$ hydrogen peroxide/methanol, as described previously (Yamakoshi et al. 2012). A streptavidin/biotin blocking kit (Vector Laboratories, Burlingame, CA, USA) was used to block endogenous biotin according to the manufacturer's instructions. After 30 min of incubation with $10 \%$ normal goat serum, the sections were incubated at $4{ }^{\circ} \mathrm{C}$ overnight with a rabbit anti-human VCAM1 polyclonal antibody (1:100 dilution, $0.5 \mathrm{mg} / \mathrm{ml}$, ab106777, Abcam, Cambridge, MA, USA), a mouse anti-human CD49d (ITGA4) antibody (1:100 dilution, $1 \mathrm{mg} / \mathrm{ml}$, MCA697GA, AbD Serotec, Hercules, CA, USA), or normal mouse IgG (1:40 dilution, $0.4 \mathrm{mg} / \mathrm{ml}$, sc-2025, Santa Cruz Biotechnology, Inc.) or normal rabbit IgG (1:80 dilution, $0.4 \mathrm{mg} / \mathrm{ml}$, sc-2027, Santa Cruz Biotechnology, Inc.) as a

Table 1 Primers for quantitative RT-PCR analyses.

\begin{tabular}{ll}
\hline $\begin{array}{l}\text { Name (GenBank } \\
\text { accession no. })\end{array}$ & Sequence \\
\hline $\begin{array}{l}\text { VCAM1 } \\
\text { (XM_005204078.1) }\end{array}$ & F: 5'-AGAAGAGCCAACATGACAGGGTCA-3' \\
& R: 5'-TCAAGGAAGCCTGAACCCCCAGT-3' \\
ITGA4 & F: 5'-TCTGGCATAGTGAGACTTGAC-3' \\
(NM_174748.1) & R: 5'-GGACTTACAAACCCATGAACTG-3' \\
$\begin{array}{l}\text { ACTB } \\
\text { (NM_173979.3) }\end{array}$ & F: 5'-TCCCTGGAGAAGAGCTACGA-3' \\
& R: 5'-GGGCAGTGATCTCTTTCTGC-3' \\
\hline
\end{tabular}

$\mathrm{F}$, forward primer; $\mathrm{R}$, reverse primer. 
negative control. Subsequently, the sections were incubated at room temperature for $1 \mathrm{~h}$ with either a goat anti-mouse IgG biotin conjugate (1:400 dilution, B7401, Sigma-Aldrich) or a goat anti-rabbit IgG biotin conjugate (1:800 dilution, B8895, Sigma-Aldrich). The immunoreactivity was visualized using the avidin-peroxidase (1:400 dilution, E2886, Sigma-Aldrich) and AEC substrate kits (Invitrogen) according to the manufacturer's instructions. The sections were counterstained with methyl green and then examined under a light microscope (BX-51, Olympus, Tokyo, Japan).

The plate of cultured EECs was fixed with $4 \%$ paraformaldehyde/PBS. After 30 min of incubation with $10 \%$ normal goat serum, the sections were incubated with a rabbit anti-human VCAM1 antibody (1:100 dilution, $0.5 \mathrm{mg} / \mathrm{ml}$, ab106777, Abcam) overnight at $4{ }^{\circ} \mathrm{C}$, and normal rabbit IgG (1:80 dilution, $0.4 \mathrm{mg} / \mathrm{ml}$, sc-2027, Santa Cruz Biotechnology, Inc.) was used as a negative control. Subsequently, the plate was incubated with a goat anti-rabbit IgG biotin conjugate (1:800 dilution, B8895, Sigma-Aldrich). The immunoreactivity was visualized by means of fluorescent conjugates of Streptavidin 568 (1:200 dilution, S11223, Invitrogen) and 4',6-diamidino-2-phenylindole (DAPI, 1:10 000 dilution, D8417, Sigma-Aldrich) for $30 \mathrm{~min}$. The images were then captured using an Olympus IX71 microscope (Olympus).

\section{Statistical analyses}

All experimental data from the bioassays represent the results obtained from three or more independent experiments each with triplicate assays, expressed as the mean \pm S.E.M. Statistical analysis was performed by Student's t-test or Dunnett's test for multiple comparisons between experimental groups using the StatView statistical analysis software (version 5; SAS Institute, Inc., Cary, NC, USA). Differences of $P<0.05$ were considered to be significant.

\section{Results}

\section{Expression of VCAM1 in the bovine uterus during the peri-attachment period}

qPCR analyses in RNAs extracted from uterine biopsy samples revealed that VCAM1 transcripts were found in endometrial tissues obtained from day 17 cyclic (C17), and days 17, 20, and 22 pregnant animals (P17, P20, and P22). Uterine VCAM1 expression was minimal in day 17 cyclic animals, was slightly up-regulated in day 17 pregnant animals, and increased by approximately fourto fivefold (vs day 17 cyclic) in days 20 and 22 pregnant animals (Fig. 1A). To confirm the up-regulation of VCAM1 expression associated with its protein, immunohistochemistry was carried out with frozen sections from day 20 pregnant uteri. VCAM1 protein was localized to the luminal and glandular epithelia of the intercaruncular regions, whereas in the caruncular regions, VCAM1 protein was detected in the stroma and endothelia of the uterine endometrium (Supplementary Figures 1 and 2, see section on supplementary data given at the end of this article).
A

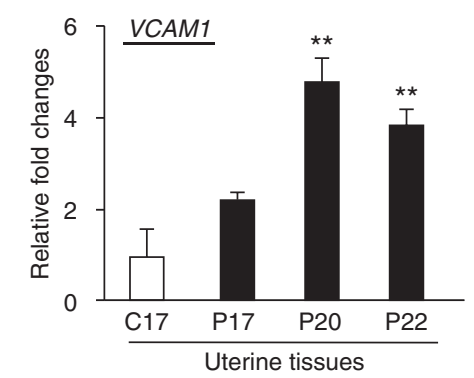

B

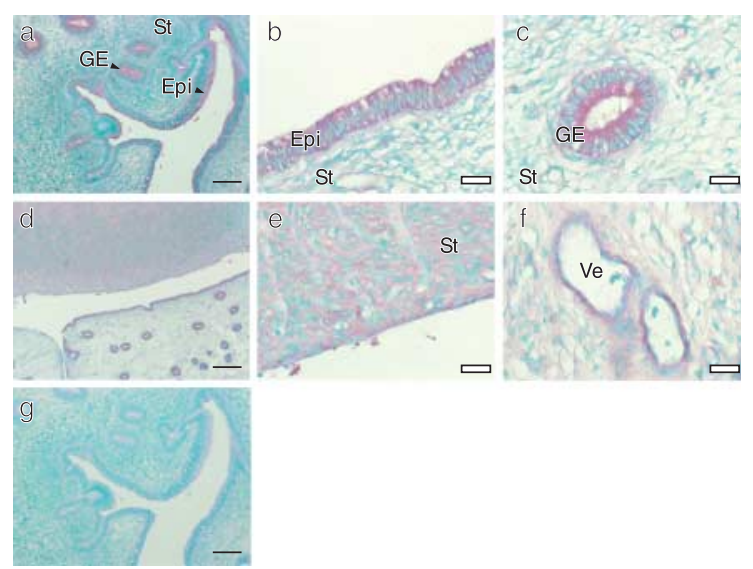

Figure 1 Expression of VCAM1 in the bovine uterus during the periattachment period. (A) Changes in VCAM1 mRNA in endometria of day 17 cyclic (day 17; C17) or pregnant animals (day 17, 20, or 22; P17, $\mathrm{P} 20$, or $\mathrm{P} 22$ respectively) ( $n=3$ each day). ACTB mRNA was used as an internal control for RNA integrity. ${ }^{* *}$ Statistically significant differences in mRNA levels $(P<0.05)$ (B) Immunohistochemical analysis of VCAM1 in the bovine uterus from day 20 pregnant animals. Tissue sections $(10 \mu \mathrm{m})$ from day 20 frozen uteri were immunostained for VCAM1 using an anti-human VCAM1 antibody (a, b, c, d, e, and f), and a negative control with the normal rabbit IgG as a primary antibody (g). (a) Low magnification showing a cross-section of the uterus, (b) uterine epithelium, (c) glandular epithelium, (d) caruncular side (upper) of the endometrium, (e) uterine stroma in the caruncular side of the

endometrium, (f) uterine vessels in the stroma, $(\mathrm{g})$ a serial section of $\mathrm{B}-\mathrm{a}$ treated with normal rabbit IgG. Epi, endometrial luminal epithelium; GE, glandular epithelium; St, endometrial stroma; Ve, uterine vessel. Black scale bar $=200 \mu \mathrm{m}$ and white scale bar $=40 \mu \mathrm{m}$.

\section{Up-regulation of VCAM1 expression in EECs treated with uterine flushings or growth factor}

qPCR was executed to determine VCAM1 mRNA expression in the RNA extracted from EECs that were treated with or without the bovine uterine flushing from day 22 pregnant animals. VCAM1 expression was up-regulated by twofold when cultured EECs were treated with the uterine flushing (Fig. 2A). These results together with those in Fig. 1 indicated that VCAM1 was expressed in the uterine endometrial epithelium. Instead of uterine flushings, EECs were then treated with EGF, bFGF, or IFNT for $48 \mathrm{~h}$ (Fig. 2B). VCAM1 mRNA expression in EECs was found to be up-regulated in all cases. To confirm if the increase in VCAM1 transcripts 


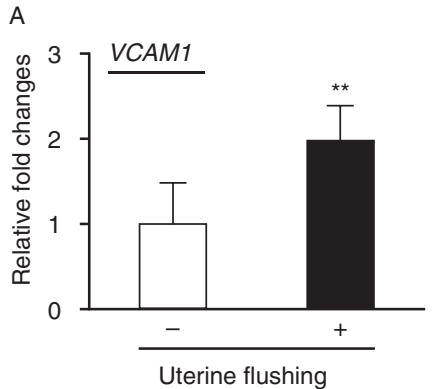

B

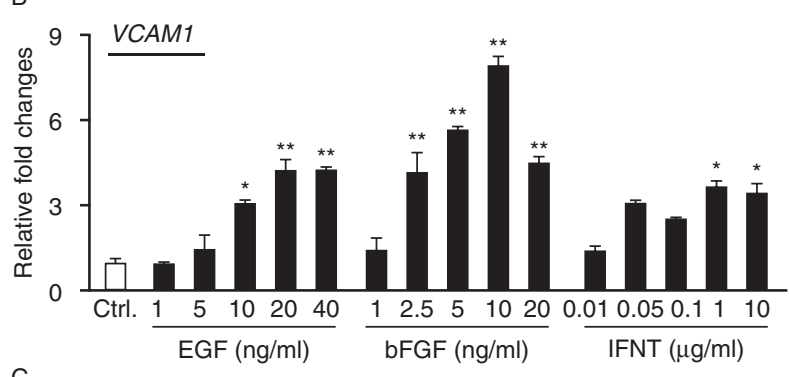

C

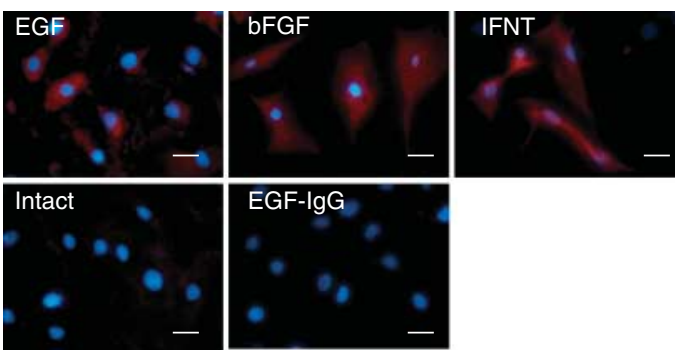

Figure 2 Up-regulation of VCAM1 expression in bovine endometrial epithelial cells (EECs) treated with uterine flushings or cytokine.

(A) Levels of VCAM1 mRNAs in monocultured EECs treated with bovine uterine flushings obtained from day 22 pregnant animals. **Statistically significant differences in mRNA levels $(P<0.01)$. (B) Up-regulation of VCAM1 transcript expression in monocultured EECs in the serum-free medium treated with $\operatorname{EGF}(1,5,10,20$, and $40 \mathrm{ng} / \mathrm{ml}), \operatorname{bFGF}(1,2.5,5$, 10 , and $20 \mathrm{ng} / \mathrm{ml})$, or IFNT $(0.01,0.05,0.1,1$, and $10 \mu \mathrm{g} / \mathrm{ml})$ for $48 \mathrm{~h}$. ACTB mRNA was used as an internal control for RNA integrity. Values represent mean \pm S.E.M. from three independent experiments with triplicates within each treatment. ${ }^{*}$ or $* *$ Statistically significant differences in mRNA levels $\left(* P<0.05,{ }^{*} P<0.01\right)$. (C) Immunofluorescence analysis of VCAM1 expression in EECs treated with EGF, bFGF, or IFNT for $48 \mathrm{~h}$. EGF: EECs cultured with EGF (20 ng/ml), bFGF: EECs cultured with bFGF $(10 \mathrm{ng} / \mathrm{ml})$, IFNT: EECs cultured with IFNT $(1 \mu \mathrm{g} / \mathrm{ml})$, Intact: EECs cultured without EGF, bFGF, or IFNT, and EGF-IgG: EECs cultured with EGF $(20 \mathrm{ng} / \mathrm{ml})$, but detected with the normal rabbit IgG (a negative control), instead of the VCAM1 antibody. VCAM1 expression is shown in red color and nuclei were counterstained with DAPI. Three independent experiments were carried out and the representative one is shown. Scale bar $=40 \mu \mathrm{m}$.

was associated with VCAM1 protein, EECs treated with EGF $(20 \mathrm{ng} / \mathrm{ml})$, bFGF $(10 \mathrm{ng} / \mathrm{ml})$, or IFNT $(1 \mu \mathrm{g} / \mathrm{ml})$ were subjected to immunofluorescence staining (Fig. 2C). The expression of VCAM1 in EECs treated with EGF, bFGF, or IFNT was enhanced when compared with those in EECs without treatment, and the VCAM1 protein was found in the cytoplasmic areas of EECs.

\section{Up-regulation of VCAM1 expression in EECs cocultured with bovine trophoblast CT1 cells}

The expression of VCAM1 transcripts was also examined in monocultured EECs as well as in EECs cocultured with CT1. EECs cocultured with CT1 cells that were placed on a shaker prevented an attachment of $\mathrm{CT} 1$ cells to EECs (Fig. 3A). The expression of VCAM1 was up-regulated by 12-fold in EECs cocultured with CT1 (Fig. 3B, upper left), exceeding the effects of day 22 pregnant uterine flushings, EGF, bFGF, or IFNT treatment (Fig. 2A and B). To confirm if the increase in VCAM1 transcripts was associated with VCAM1 protein, EECs cocultured with CT1 placed on a gentle shaker for $48 \mathrm{~h}$ were subjected to immunofluorescence staining (Fig. 3B). The expression of VCAM1 in EECs cocultured with CT1 cells was
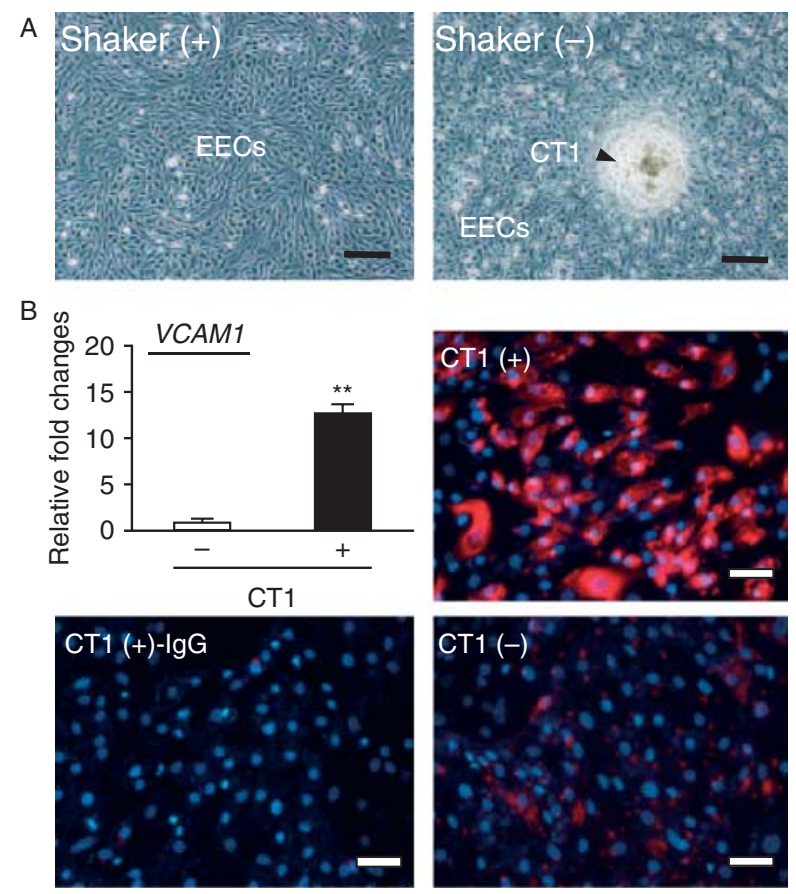

Figure 3 Up-regulation of VCAM1 expression in bovine endometrial epithelial cells (EECs) cocultured with bovine trophoblast CT1 cells. (A) Coculture of EECs with CT1 cells with or without a shaker. When EECs cocultured with CT1 cells were placed on a shaker for $48 \mathrm{~h}, \mathrm{CT} 1$ cells did not attach to EECs (A left), whereas those without a shaker exhibited CT1 attachment to EECs (A right). Scale bar $=200 \mu \mathrm{m}$.

(B) Upper left: up-regulation of VCAM1 transcript expression in EECs cultured with (+) or without (-) CT1 cells. ACTB mRNA was used as an internal control for RNA integrity. Values represent mean \pm S.E.M. from three independent experiments with triplicates within each experiment. ${ }^{*}$ Statistically significant differences in mRNA levels $(P<0.01)$. (B) Upper right and bottom two: immunofluorescence analysis of VCAM1 in EECs cocultured with CT1 cells for 48 h. CT1 (+): EECs cocultured with CT1 cells, and CT1 (+)-lgG: EECs cocultured with CT1, and instead of the VCAM1 antibody, cells were treated with the normal rabbit IgG (a negative control), CT1 (-): monocultured EECs. VCAM1 expression is shown in red color, and nuclei were counterstained with DAPI. Three independent experiments were carried out and the representative one is shown. White scale bar $=80 \mu \mathrm{m}$. 
enhanced when compared with monocultured EECs. Moreover, the protein was found in the cytoplasmic region of EECs, revealing that cell-cell interaction with CT1 cells could enhance VCAM1 expression in EECs.

\section{Expression and regulation of VCAM1 transcripts in the bovine conceptus during the peri-attachment period}

qPCR analyses in RNAs extracted from bovine conceptuses obtained from days 17, 20, and 22 pregnant animals revealed that VCAM1 transcript expression was minimal in days 17 and 20 conceptuses before increasing by 200 -fold in day 22 conceptuses (Fig. 4A). qPCR was also executed to determine VCAM1 mRNA expression in RNA extracted from monocultured CT1 cells treated with the bovine uterine flushing from day 22 pregnant or cocultured CT1 cells with EECs. Although VCAM1 was not found in CT1 cells without treatment, up-regulated transcripts were found when $\mathrm{CT} 1$ cells were treated with

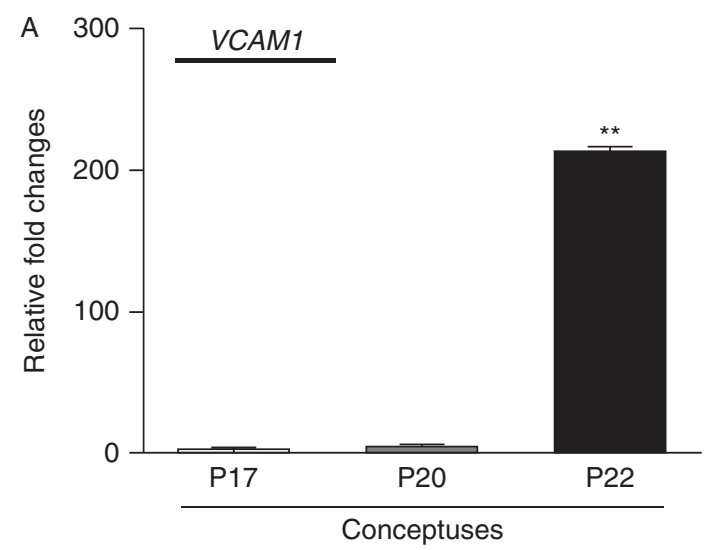

B

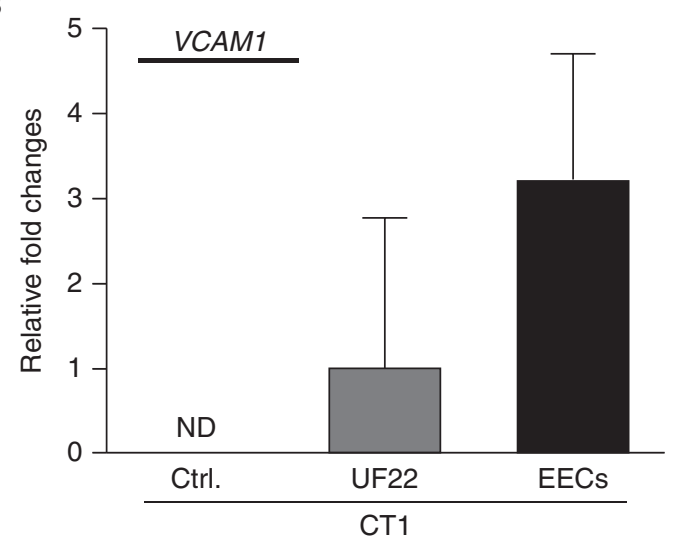

Figure 4 Expression and regulation of VCAM1 transcripts in bovine conceptuses during the peri-attachment period. (A) Changes in VCAM1 mRNAs in days 17, 20, and 22 conceptuses (P17, P20, and P22 respectively). (B) Up-regulation of VCAM1 mRNA expression in CT1 cells treated with uterine flushings obtained from day 22 pregnant animals (UF22) or cocultured with EECs (EECs). Values represent mean \pm S.E.M. from three independent samples with duplicates within a treatment. ${ }^{* *}$ Statistically significant differences in mRNA levels $(P<0.01)$. the uterine flushing from day 22 pregnant animals and further increased in VCAM1 transcripts in CT1 cells cocultured with EECs (Fig. 4B). These results indicated that similar to VCAM1 expression in EECs, up-regulation of VCAM1 expression in CT1 cells could result from cellcell interactions between trophoblasts and uterine EECs.

\section{The expression of VCAM1 receptor, ITGA4, by bovine conceptus}

qPCR analyses in RNAs extracted from bovine conceptuses obtained from days 17, 20, and 22 pregnant animals revealed that ITGA4 expression was minimal in days 17 and 20 conceptuses, while a 6000-fold increase in ITGA4 expression was found in day 22 conceptuses (Fig. 5A), but ITGA4 mRNA expression was minimal at the uterine endometrium in days 17,20, and 22 pregnant animals (results not shown). The expression of ITGA4 and its ligand VCAM1 in frozen uterine sections isolated from day 22 pregnant animals were determined by immunohistochemistry (Fig. 5B). ITGA4 was localized to the trophoblast cells, but not to the maternal side, while VCAM1 was found in both trophoblast cells and EECs.

\section{Discussion}

VCAM1 is well known as a cell adhesion mediator during the process of lymphocyte homing (May et al. 1993), angiogenesis (Ding et al. 2003), and allantoic membrane fusion to the chorion (Gurtner et al. 1995). In this study, VCAM1 expression was detected at the trophoblast and uterine epithelium, as well as uterine glandular epithelium and endothelium, during the periimplantation period. In endothelial cells, VCAM1 is induced by cytokines such as tumor necrosis factor $\alpha$ produced by leukocytes (Henninger et al. 1997). The increase in VCAM1 leads to the production of more chemokines by the endothelial cells, which attract and proceed with the migration of leukocytes into these cells (Wittchen 2009). During the process of conceptus attachment to the endometrium in cattle, increases in VCAM1 and its protein expression in the cytoplasm of cultured EECs were detected when treated with the uterine flushings obtained from day 22 pregnant animals, growth factor (EGF or bFGF), or IFNT. However, VCAM1 expression was further up-regulated when EECs were cocultured with bovine trophoblast CT1 cells. More importantly, the degree of up-regulation of VCAM1 mRNA expression was more significant in cocultured EECs than in monocultured EECs treated with uterine molecules, and a similar degree of up-regulation was also found in VCAM1 transcript expression in cocultured CT1. Based on these observations, both cell-cell interactions between the conceptus and uterine epithelium and uterine molecules, found in the uterine flushings obtained from day 22 conceptuses, could induce VCAM1 production in the endometrium and/or 
A

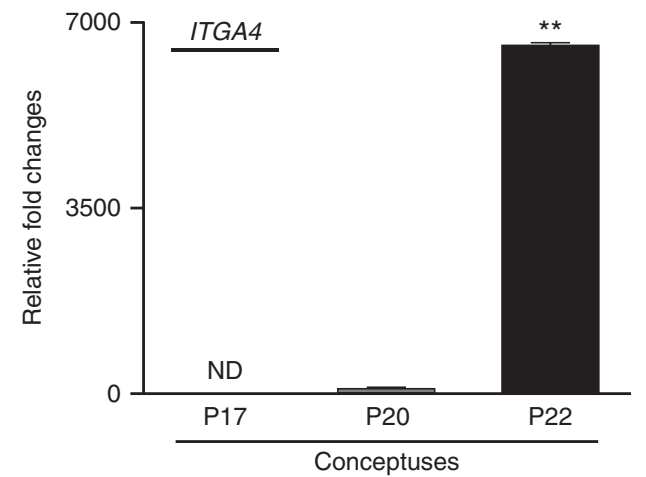

B

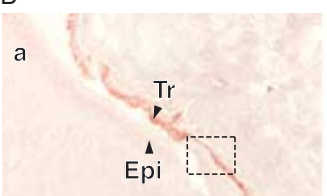

St
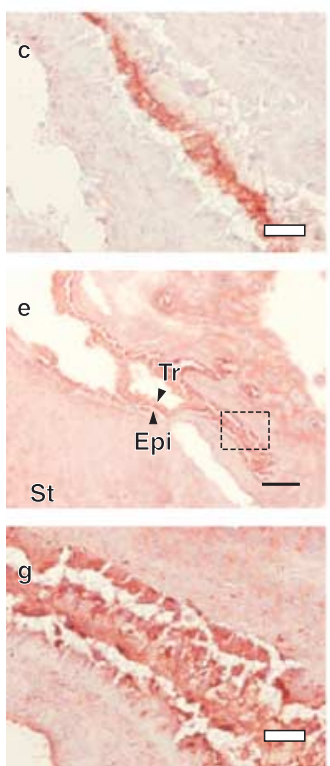

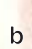

b
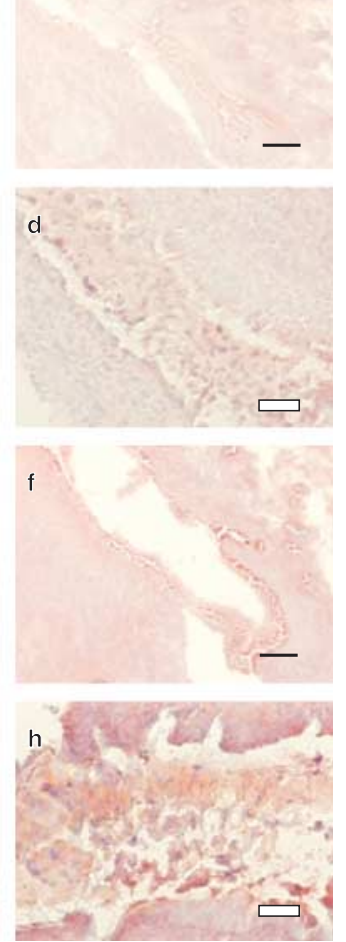

Figure 5 Expression of VCAM1 receptor, integrin $\alpha 4$ (ITGA4), by bovine conceptuses. (A) Changes in ITGA4 mRNAs in days 17, 20, and 22 conceptuses (P17, P20, and P22 respectively). Note that ITGA4 transcripts were found minimal at the uterine epithelium and stroma. Values represent mean \pm S.E.M. from three independent samples with duplicates within a day of conceptus collection. ${ }^{* *}$ Statistically significant differences in mRNA levels $(P<0.01)$. (B) Immunohistochemical analysis of ITGA4 (a, b, c, and d) or VCAM1 (e, f, g, and h) expression in the bovine uterus obtained from day 22 pregnant animals. Tissue sections $(10 \mu \mathrm{m})$ from day 22 uteri were immunostained for ITGA4 using an anti-ITGA4 antibody ( $\mathrm{a}$ and $\mathrm{c}$ ) or normal mouse $\operatorname{lgG}$ as a negative control at low (b) and higher magnification (d). (c) Observation of boxed area in B-a at a higher magnification.

Tissue sections were immunostained for VCAM1 using an anti-VCAM1 antibody (e and g), or normal rabbit lgG as a negative control at low (f) and higher magnification (h). (g) Observation of boxed area in B-e at a higher magnification. Epi, endometrial luminal epithelium; St, endometrial stroma; $\mathrm{Tr}$, trophoblast. Black scale bar $=200 \mu \mathrm{m}$ and white scale bar $=40 \mu \mathrm{m}$.

conceptuses. These results strongly suggest that VCAM1 is required as at least one of cell adhesion mediators for bovine conceptus attachment and/or adhesion to the uterine luminal epithelium.

VLA4, composed of integrin $\alpha 4$ (ITGA4, CD49D) and integrin $\beta 1$ (ITGB1, CD29), has been found as a receptor for VCAM1, and the complex is known to function in the process of arresting rolling monocytes within blood vessels (Chu et al. 2013) and cancer cell-endothelial cell adhesion (Song et al. 2012). Patients with unexplained infertility exhibited a marked decrease in VCAM1 expression in the endometrium in the late secretory phase, coincident with the implantation window (Konac et al. 2009). These investigators suggested that downregulated uterine VCAM1 expression may result in asynchrony of uterine development for conceptus implantation. In this study, ITGA4 transcript expression was significantly up-regulated in day 22 conceptuses (Fig. 5A), and at the same time, VCAM1 mRNA level was also increased in uterine tissues (Fig. 1A). More importantly, VCAM1 protein was localized to both trophoblast cells and EECs while ITGA4 was found only in the trophoblast cells in frozen uterine sections from day 22 pregnant animals. These observations indicated that concomitant expression of VCAM1 and ITGA4 on day 22 could be a prerequisite for bovine conceptus adhesion and suggest that the expression of VCAM1 and ITGA4 represent a developmental synchrony between trophectoderm and uterine epithelium for conceptus implantation to proceed.

It has been thought that implantation is a cell biological paradox because apical plasma membranes of trophoblast and uterine luminal epithelia are non-adhesive (Denker 1993). In our previous observations (Yamakoshi et al. 2012), up-regulation of mesenchymal markers, $\mathrm{N}$-cadherin and vimentin, and some ITGs including ITGA4 occurs simultaneously in day 22 bovine conceptuses, while the blastocyst still expresses an epithelial marker, cytokeratin. Increases in the expression of these genes represent the epithelial-mesenchymal transition of trophoblasts (EMT). However, the expression of both epithelial and mesenchymal markers are rather transient, and thus, this transition is a partial EMT (Yamakoshi et al. 2012). In addition to partial EMT on day 22, the up-regulation of the VCAM1/ITGA4 complex may aid in attachment and/or adhesion processes between trophoblasts and uterine epithelium. Furthermore, it is well established that matrix metalloproteases (MMPs) play a role in the process of trophoblast invasion during the implantation period in humans and rodents (Cohen et al. 2006). The increase in MMPs in day 22 bovine conceptuses was also noted previously (Yamakoshi et al. 2012). It is reported that VCAM1 activates endothelial cell MMPs through reactive oxygen species during lymphocyte migration (Deem \& Cook-Mills 2004). Thus, up-regulated expression of VCAM1/ITGA4 as well as MMPs in day 22 conceptuses within uterine environments 
could also be associated with attachment and/or adhesion processes in the limited invasive mode of ruminant implantation.

In conclusion, this study indicates that the expression of VCAM1 can be up-regulated by the molecules present in uterine flushings, but VCAM1 expression is significantly increased by the cell-cell interactions between conceptus and uterine epithelial cells. Therefore, following the initiation of cell-cell interaction (attachment) processes, VCAM1 together with its receptor, ITGA4, is likely to be required for conceptus adhesion to the endometrial epithelium in the bovine species.

\section{Supplementary data}

This is linked to the online version of the paper at http://dx.doi. org/10.1530/REP-13-0655.

\section{Declaration of interest}

The authors declare that there is no conflict of interest that could be perceived as prejudicing the impartiality of the research reported.

\section{Funding}

This work was supported by a Grant-in-Aid for Young Scientists (B) 25850183 (to T Sakurai) from the Japan Society for the Promotion of Science (JSPS) and by the Science and Technology Research Promotion Program for Agriculture, Forestry, Fisheries and Food Industry (to K Imakawa).

\section{Acknowledgements}

The authors would like to thank Dr Alan Ealy, Virginia Polytechnic Institute, for the gift of bovine CT1 cells. The authors also extend their appreciation to Mr. Youichi Noguchi and Dr. Kazue Okubo (Genostaff, Tokyo, Japan) for the execution and advice of immunohistochemical analysis.

\section{References}

Akiyama SK 1996 Integrins in cell adhesion and signaling. Human Cell 9 181-186.

Aplin AE, Howe A, Alahari SK \& Juliano RL 1998 Signal transduction and signal modulation by cell adhesion receptors: the role of integrins, cadherins, immunoglobulin-cell adhesion molecules, and selectins. Pharmacological Reviews 50 197-263.

Armant DR 2005 Blastocysts don't go it alone. Extrinsic signals fine-tune the intrinsic developmental program of trophoblast cells. Developmental Biology 280 260-280. (doi:10.1016/j.ydbio.2005.02.009)

Bustin SA, Benes V, Garson JA, Hellemans J, Huggett J, Kubista M, Mueller R, Nolan T, Pfaffl MW, Shipley GL et al. 2009 The MIQE guidelines: minimum information for publication of quantitative realtime PCR experiments. Clinical Chemistry 55 611-622. (doi:10.1373/ clinchem.2008.112797)

Chu C, Celik E, Rico F \& Moy VT 2013 Elongated membrane tethers, individually anchored by high affinity $\alpha 4 \beta 1$ NCAM-1-1 complexes, are the quantal units of monocyte arrests. PLOS ONE 8 64187. (doi:10.1371/ journal.pone.0064187)
Cohen M, Meisser A, Haenggeli L \& Bischof P 2006 Involvement of MAPK pathway in TNF- $\alpha$-induced MMP-9 expression in human trophoblastic cells. Molecular Human Reproduction 12 225-232. (doi:10.1093/ molehr/gal023)

Deem TL \& Cook-Mills JM 2004 Vascular cell adhesion molecule 1 (VCAM-1) activation of endothelial cell matrix metalloproteinases: role of reactive oxygen species. Blood 104 2385-2393. (doi:10.1182/ blood-2004-02-0665)

Denker HW 1993 Implantation: a cell biological paradox. Journal of Experimental Zoology 266 541-558. (doi:10.1002/jez.1402660606)

Denucci CC, Mitchell JS \& Shimizu Y 2009 Integrin function in T-cell homing to lymphoid and nonlymphoid sites: getting there and staying there. Critical Reviews in Immunology 29 87-109. (doi:10.1615/ CritRevImmunol.v29.i2.10)

Ding YB, Chen GY, Xia JG, Zang XW, Yang HY \& Yang L 2003 Association of VCAM-1 overexpression with oncogenesis, tumor angiogenesis and metastasis of gastric carcinoma. World Journal of Gastroenterology 9 1409-1414.

Diskin MG \& Morris DG 2008 Embryonic and early foetal losses in cattle and other ruminants. Reproduction in Domestic Animals 2 260-267. (doi:10.1111/j.1439-0531.2008.01171.x)

Farmer JL, Burghardt RC, Jousan FD, Hansen PJ, Bazer FW \& Spencer TE 2008 Galectin 15 (LGALS15) functions in trophectoderm migration and attachment. FASEB Journal 22 548-560. (doi:10.1096/fj.07-9308com)

Gurtner GC, Davis V, Li H, McCoy MJ, Sharpe A \& Cybulsky MI 1995 Targeted disruption of the murine VCAM-1 gene: essential role of VCAM-1 in chorioallantoic fusion and placentation. Genes and Development 9 1-14. (doi:10.1101/gad.9.1.1)

Henninger DD, Panés J, Eppihimer $M$, Russell J, Gerritsen $M$, Anderson DC \& Granger DN 1997 Cytokine-induced VCAM-1 and ICAM-1 expression in different organs of the mouse. Journal of Immunology 158 1825-1832.

Ideta A, Urakawa M, Aoyagi Y \& Saeki K 2007 Early development in utero of bovine nuclear transfer embryos using early G1 and G0 phase cells. Cloning Stem Cells 9 571-580. (doi:10.1089/clo.2007.0017)

Konac E, Alp E, Onen HI, Korucuoglu U, Biri AA \& Menevse S 2009 Endometrial mRNA expression of matrix metalloproteinases, their tissue inhibitors and cell adhesion molecules in unexplained infertility and implantation failure patients. Reproductive Biomedicine Online 19 391-397. (doi:10.1016/S1472-6483(10)60174-5)

Macintyre DM, Lim HC, Ryan K, Kimmins S, Small JA \& MacLaren LA 2002 Implantation-associated changes in bovine uterine expression of integrins and extracellular matrix. Biology of Reproduction 66 1430-1436. (doi:10.1095/biolreprod66.5.1430)

MacLaren LA \& Wildeman AG 1995 Fibronectin receptors in preimplantation development: cloning, expression, and localization of the $\alpha 5$ and $\beta 1$ integrin subunits in bovine trophoblast. Biology of Reproduction 53 153-165. (doi:10.1095/biolreprod53.1.153)

May MJ, Entwistle G, Humphries MJ \& Ager A 1993 VCAM-1-1 is a CS1 peptide-inhibitable adhesion molecule expressed by lymph node high endothelium. Journal of Cell Science 106 109-119.

Nagaoka K, Nojima H, Watanabe F, Chang KT, Christenson RK, Sakai S \& Imakawa K 2003 Regulation of blastocyst migration, apposition, and initial adhesion by a chemokine, interferon gamma-inducible protein 10 kDa (IP-10), during early gestation. Journal of Biological Chemistry 278 29048-29056. (doi:10.1074/jbc.M300470200)

Osborn L, Hession C, Tizard R, Vassallo C, Luhowskyj S, Chi-Rosso G \& Lobb R 1989 Direct expression cloning of vascular cell adhesion molecule 1, a cytokine-induced endothelial protein that binds to lymphocytes. Cell 59 1203-1211. (doi:10.1016/0092-8674(89)90775-7)

Pfarrer CD 2006 Characterization of the bovine placenta by cytoskeleton, integrin receptors, and extracellular matrix. Methods in Molecular Medicine 121 323-335.

Pfarrer C, Hirsch P, Guillomot M \& Leiser R 2003 Interaction of integrin receptors with extracellular matrix is involved in trophoblast giant cell migration in bovine placentomes. Placenta 24 588-597. (doi:10.1016/ S0143-4004(03)00059-6)

Rahman AN, Snibson KJ, Lee CS \& Meeusen EN 2004 Effects of implantation and early pregnancy on the expression of cytokines and vascular surface molecules in the sheep endometrium. Journal of Reproductive Immunology 64 45-58. (doi:10.1016/j.jri.2004.08.008) 
Sakurai T, Bai H, Bai R, Arai M, Iwazawa M, Zhang J, Konno T, Godkin JD, Okuda K \& Imakawa K 2012 Coculture system that mimics in vivo attachment processes in bovine trophoblast cells. Biology of Reproduction 87 1-11. (doi:10.1095/biolreprod.112.100180)

Simmons RM, Erikson DW, Kim J, Burghardt RC, Bazer FW, Johnson GA \& Spencer TE 2009 Insulin-like growth factor binding protein-1 in the ruminant uterus: potential endometrial marker and regulator of conceptus elongation. Endocrinology 150 4295-4305. (doi:10.1210/en. 2009-0060)

Skarzynski DJ, Miyamoto Y \& Okuda K 2000 Production of prostaglandin F2 by cultured bovine endometrial cells in response to tumor necrosis factor: cell type specificity and intracellular mechanisms. Biology of Reproduction 62 1116-1120. (doi:10.1095/biolreprod62.5. 1116)

Song K, Zhu F, Zhang HZ \& Shang ZJ 2012 Tumor necrosis factor- $\alpha$ enhanced fusions between oral squamous cell carcinoma cells and endothelial cells via VCAM-1/VLA-4 pathway. Experimental Cell Research 318 1707-1715. (doi:10.1016/j.yexcr.2012.05.022)

Stephens LE, Sutherland AE, Klimanskaya IV, Andrieux A, Meneses J, Pedersen RA \& Damsky CH 1995 Deletion of $\beta 1$ integrins in mice results in inner cell mass failure and peri-implantation lethality. Genes and Development 9 1883-1895. (doi:10.1101/gad.9. 15.1883)

Talbot NC, Caperna TJ, Edwards JL, Garrett W, Wells KD \& Ealy AD 2000 Bovine blastocyst-derived trophectoderm and endoderm cell cultures: interferon tau and transferrin expression as respective in vitro markers. Biology of Reproduction 62 235-247. (doi:10.1095/biolreprod62.2.235)

Wittchen ES 2009 Endothelial signaling in paracellular and transcellular leukocyte transmigration. Frontiers in Bioscience 14 2522-2545. (doi:10.2741/3395)

Yamakoshi S, Bai R, Chaen T, Ideta A, Aoyagi Y, Sakurai T, Konno T \& Imakawa K 2012 Expression of mesenchymal-related genes by the bovine trophectoderm following conceptus attachment to the endometrial epithelium. Reproduction 143 377-387. (doi:10.1530/REP-11-0364)

Yang JT, Rayburn H \& Hynes RO 1995 Cell adhesion events mediated by $\alpha 4$ integrins are essential in placental and cardiac development. Development 121 549-560.

Zeiler M, Leiser R, Johnson GA, Tinneberg HR \& Pfarrer C 2007 Development of an in vitro model for bovine placentation: a comparison of the in vivo and in vitro expression of integrins and components of extracellular matrix in bovine placental cells. Cells, Tissues, Organs 186 229-242. (doi:10.1159/000107947)

Received 18 December 2013

First decision 6 January 2014

Revised manuscript received 30 April 2014

Accepted 6 May 2014 